\title{
DESIGN OF HAUNCHES IN STRUCTURAL STEEL JOINTS
}

\author{
Marta KUREJKOVÁ, František WALD \\ Department of Steel and Timber Structures, Faculty of Civil Engineering, \\ Czech Technical University in Prague, Thákurova 7, 16629 Prague 6, Czech Republic
}

Received 20 Sep 2016; accepted 21 Nov 2016

\begin{abstract}
The paper presents research in design of haunches in structural steel joints. Experimental results of six specimens of haunches with and without flanges are presented. Three specimens are without flanges and three specimens are supported by additional flanges. Flanges differ in stiffness to observe the increase in haunch resistances and the effect on buckling shapes. The research finite element model (RFEA) is studied by material and geometrical nonlinear finite element analysis with imperfections under the actual stress conditions and validated on the measured experimental data. The validity is demonstrated on the comparison of load-deflection curves, failure modes, stress distributions and yield line patterns. The stability analysis of a joint with a haunch is related to the research into component based finite element models of complex joints. The input and the results of the research finite element model are summarised in a benchmark case of a haunch with a flange. A numerical study illustrates the effect of the flange stiffness on the joint's resistance. The effect is demonstrated on a simple arrangement with triangular stiffeners and on a beam-to-column joint. The main goal of the research is to verify proposed design procedure for stiffeners in steel joints.
\end{abstract}

Keywords: structural steel joint, haunch, stiffener, experimental study, buckling, component based finite element model, validation, numerical modelling.

\section{Introduction}

Stiffeners in the joints of steel structures are designed as triangular steel plates which have free, partially stiffened or clamped edges. Experimental results reviewed in Shi et al. (2007) and Abidelah et al. (2012) indicate clearly that the presence of stiffeners in the extended end-plate connections has a great influence on the behaviour of the joints.

The component method described in Sec. 6 EN 1993-1-8:2006 is commonly used for the design of joints in steel structures. The basic idea of the method is to divide the joint into individual components. For each component, mechanical characteristics are determined, particularly its design resistance and initial stiffness. The design resistance and initial stiffness of the whole joint are determined by the assembly of individual components.

In EN 1993-1-8:2006 Section 6.2.6.7, the beam flange and web in compression, general rules for the design of haunches are specified, based on research done by Zoetemeijer (1981a, 1981b). It is recommended using the same or higher plate thickness and steel grade for the haunch web and flange as for the beam flange. The typical haunch is designed as a first or second class crosssection which allows the plastic design. Fourth class stiff- eners such as haunches with a partially stiffened edge, thin web haunches or haunches without flanges are not covered in the design code, although the design resistance of the above mentioned joint is significantly increased by adding stiffeners to the compressed side of the joint as is proved in Kurejková and Wald (2014). The resistance of three typical beam-to-column joints is compared. The numerical analysis shows the increase in the resistance of a welded beam-to-column joint by $25 \%$ when partially stiffened haunch or haunch without flange is used compared to unstiffened one.

In the past 30 years, many studies have focused on the design of triangular stiffeners with a free edge. Design methods are published in Martin (1979), Shakya and Vinnakota (2008) and Laustsen et al. (2012). A large experimental investigation is published in (Robinson 1983) and (Salmon et al. 1964). All methods are not ready to be adopted directly in the component method or in numerical calculations, because the estimation of the failure mechanism is required. In the last decade researchers proposed formulas for calculating rotational stiffness and strengths with component method in the extended endplate connections (Zhao, Quian 2011).

Corresponding author: Marta Kurejková

E-mail: marta.kurejkova@fsv.cvut.cz 
Haunches are widely used in seismic moment connections. Brittle fractures in steel moment connections caused by earthquakes motivated engineers to design a connection with plastic areas away from the column flange. Welding a triangular haunch has been shown to be very effective in both seismic steel (Yu et al. 2000) and composite (Shanmugam et al. 2002) and (Lachal et al. 2005) connections. To minimize the construction cost new arrangements are proposed. The study by Lee (Lee et al. 2003) is focused on a straight haunch with one free end and a seismic design procedure based on a strut model is described (Lee 2002). Hoang proposed using a hammer head (Hoang et al. 2014). The dimensions make the haunch fabrication easier if it is cut out directly from a steel beam. All proposed variations only allow plastic design according to EN 1993-1-8:2006.

Practice is asking for a design method for a general plate, which is not limited to plastic design only but also covers fourth class cross sections. The design method should be fully adapted to advanced FEM analysis. Design approaches based on advanced finite element analysis are described in Annex C EN 1993-1-5:2008. The code provides a recommendation in the design of steel structures giving the general alternative of using different levels of numerical analysis instead of standardized formulas. A numerical study focused on buckling analysis using advanced numerical modelling is described in Vigh and Dunai (2010).

Each type of the above mentioned stiffeners has a different design procedure and limits the stiffener size by the recommended plate thickness or dimensions. The design procedure for general plate dimensions is not available and joints for which the component method is not applicable are analysed by the finite element method (FEA). The research FEA model (RFEA), which is based on materially and geometrically nonlinear analysis with imperfections (GMNIA), is not suitable for the design of common joints, especially for time-consuming modelling, difficulties in entering the imperfections and the definition of the ultimate limit state. On the other hand, the component based FEA model (CBFEM) with material nonlinear analysis without imperfections and with the assessment of the components of bolts, welds and plates becomes an alternative approach to the design of joints as is described in Gödrich et al. (2014) and Wald et al. (2014). The design of fourth class stiffeners in the joints of steel structures takes into account local buckling of a slender compressed plate, shear buckling of a slender web panel and local buckling of a compressed plate between the bolts (see Kurejková et al. 2015).

In the first part of the study, haunches and haunches without flanges are studied by laboratory tests with the detailed measurement of deflections and strains. In the second part, the resistance is calculated and validated against experimental data. For the research FEA model (RFEA) validation purposes, material and geometrical nonlinear finite element analysis with imperfections is applied. The input data and the results of one RFEA are summarised in a benchmark case. The application of validation in the design of steel connections is limited to a few published benchmark studies (see Bursi and Jaspart 1997). These cases are applied by users to check their systems when following the input data and comparing them with the results. The research is extended by a numerical study of haunches in a beam-to-column joint.

\section{Experimental results}

This section describes the experimental investigation of haunches with and without flanges. Tensile tests of the used steel plates are part of the experimental program. The experiments were carried out in cooperation with the Experimental Centre, Faculty of Civil Engineering, CTU in Prague. The main goal was to evaluate the influence of the flange stiffness in connections with haunches.

\subsection{Tensile tests}

Specimens for the tensile test are manufactured from the same steel grade as the haunches. The steel grade specified for all plates is S355. Six specimens are tested for plate thicknesses of 4 and $6 \mathrm{~mm}$, and three specimens for a thickness of $12 \mathrm{~mm}$. The material properties for plate thickness of $20 \mathrm{~mm}$ are not measured. The average values of Young's Modulus, yield strength, tensile strength and elongation for plate thicknesses of 4, 6 and $12 \mathrm{~mm}$ are shown in Table 1.

Table 1. Average values of material characteristics

\begin{tabular}{l|c|c|c|c}
\hline \multicolumn{2}{c|}{ Material characteristics } & $4 \mathrm{~mm}$ & $6 \mathrm{~mm}$ & $12 \mathrm{~mm}$ \\
\hline Young's Modulus & $\begin{array}{c}E \\
{[\mathrm{GPa}]}\end{array}$ & 163.0 & 158.7 & 159.8 \\
Yield strength & $\begin{array}{c}f_{y} \\
{[\mathrm{MPa}]}\end{array}$ & 417.5 & 323.5 & 395.4 \\
Tensile strength & $\begin{array}{c}f_{u} \\
{[\mathrm{MPa}]}\end{array}$ & 499.3 & 467.0 & 529.6 \\
Elongation & $A[\%]$ & 15.1 & 20.2 & 26.2 \\
\hline
\end{tabular}

The material characteristics are determined at room temperature. Stresses and strains obtained in the tensile tests are converted into the true stress and strain according to:

$$
\begin{gathered}
\sigma_{\text {true }}=\sigma(1+\varepsilon) ; \\
\varepsilon_{\text {true }}=\ln (1+\varepsilon),
\end{gathered}
$$

where $\sigma_{\text {true }}$ is the true stress, $\varepsilon_{\text {true }}$ the true strain, $\sigma$ the nominal stress and $\varepsilon$ the nominal strain.

\subsection{Haunch tests}

The experiment of haunches covered six specimens with different types of edge reinforcement. Three specimens called $\mathrm{A}$ to $\mathrm{C}$ are without flanges, three specimens called 
$\mathrm{D}$ to $\mathrm{F}$ have flanges with different stiffness. Unstiffened specimens differ in the web thickness $t_{\mathrm{w}}$ and the web width $b_{\mathrm{w}}$. Reinforced specimens differ in the web thickness $t_{\mathrm{w}}$, the flange thickness $t_{\mathrm{f}}$ and the flange width $b_{\mathrm{f}}$. The dimensions of specimens are summarized in Table 2. Vertical and horizontal plates with a thickness of $20 \mathrm{~mm}$ are welded to each other. In the inner corner of the triangular web, there is a cut-out for a better fit and weld to the vertical and horizontal plates. The flange is welded to the triangular web and to both plates.

Table 2. Specimens' geometry

\begin{tabular}{c|c|c|c|c|c}
\hline \multirow{2}{*}{ Specimen } & \multicolumn{3}{|c|}{ Triangular web } & \multicolumn{2}{c}{ Flange } \\
\cline { 2 - 6 } & $\begin{array}{c}b_{\mathrm{w}} \\
{[\mathrm{mm}]}\end{array}$ & $\begin{array}{c}h_{\mathrm{w}} \\
{[\mathrm{mm}]}\end{array}$ & $\begin{array}{c}t_{\mathrm{w}} \\
{[\mathrm{mm}]}\end{array}$ & $\begin{array}{c}b_{\mathrm{f}} \\
{[\mathrm{mm}]}\end{array}$ & $\begin{array}{c}t_{\mathrm{f}} \\
{[\mathrm{mm}]}\end{array}$ \\
\hline $\mathrm{A}$ & 200 & 400 & 6 & - & - \\
$\mathrm{B}$ & 400 & 400 & 6 & - & - \\
$\mathrm{C}$ & 400 & 400 & 4 & - & - \\
$\mathrm{D}$ & 400 & 400 & 6 & 60 & 6 \\
$\mathrm{E}$ & 400 & 400 & 6 & 120 & 12 \\
$\mathrm{~F}$ & 400 & 400 & 4 & 120 & 12 \\
\hline
\end{tabular}

The test set-up is shown in Figure 1. Hydraulic press is presented to apply vertical load at the top of the specimen. Lateral torsional buckling is prevented by lateral supports. Hinges are used at the bottom. Loading is carried out in predetermined steps until the collapse of the specimen. Every test starts with loading to approximately one tenth of the load capacity determined on numerical models before testing followed by complete unloading. Then, the specimens are reloaded to the collapse.

The measured quantities are load, vertical and horizontal displacements and strains in predefined places. Displacements are measured by the inductive position sensor. Vertical displacements are measured on the horizontal plate in the middle point. Horizontal displacements are measured on the triangular webs and flanges where they are presented in the place with the expected maximum.

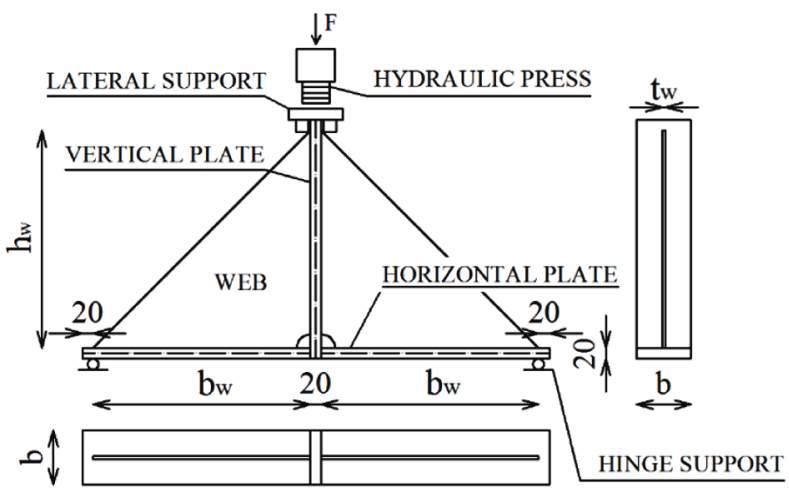

Fig. 1. Test set-up

\subsection{Haunch without a flange}

In the tests of haunches without a flange, the collapse occurs by buckling of the triangular web. The yield line in specimen $\mathrm{B}$ and $\mathrm{C}$, which have the same height and width, occurs at an angle of 45 degrees measured from the horizontal plate. A crack appears in the horizontal plate in the middle section as is shown in Figure 2. As was predicted, the haunch with a web thickness of $6 \mathrm{~mm}$ has a higher load capacity than the stiffener with a web thickness of $4 \mathrm{~mm}$. The highest load capacity and the lowest vertical and horizontal deformations are reported on the half-width specimen A. It has a yield line at an angle of 30 degrees measured from the horizontal plate.

The behaviour is described by load-deflection $(F-\delta)$ curves, where $F$ represents the applied load and $\delta$ stands for the vertical or horizontal deflection. The load-deflection curves for specimens without flanges in the vertical and horizontal direction are presented in Figure 3. Both curves show that specimen A behaves linearly up to $90 \%$ of the maximal load. On the other hand, specimen B and $\mathrm{C}$ have short linear behaviour and yield faster. Large deformations are enabled by the effect of membrane stresses and the post-buckling reserve is significant.

\subsection{Haunch with a flange}

Specimens stiffened with a flange exhibit collapse by local buckling of webs and flanges. Specimens $\mathrm{E}$ and $\mathrm{F}$ with thicker flanges buckle in a plane, see Figure 5 and Figure 6, in contrast to specimen D shown in Figure 4, which has larger out of plane deflections. When a quarter of the maximum load is applied on specimen $\mathrm{D}$, local buckling of the flange in the weld cut-out area occurs as is shown in Figure 4. With the increasing load, yielding starts in the flange. As the loading continues, yielding is significant in the triangular web. At the end flange and web buckle out of the web plane. Yielding on specimen $\mathrm{E}$ and $\mathrm{F}$ starts in flanges. The yielding in the web has similar progress along the flange. The collapse occurs when the flange load carrying capacity is exhausted.

Load-deflection curves for specimens with flanges in the vertical and horizontal direction are presented in Figure 7. The thickness of the triangular web in the configuration with a very stiff flange has no influence on the resistance as is shown by the curves for specimen $\mathrm{E}$ and $\mathrm{F}$. The web horizontal deformation is affected by the buckling shape of the flange as is shown by curve F. In
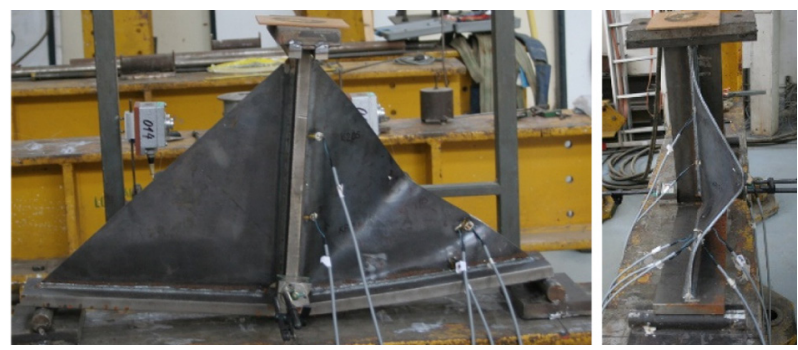

Fig. 2. Specimen B after testing 

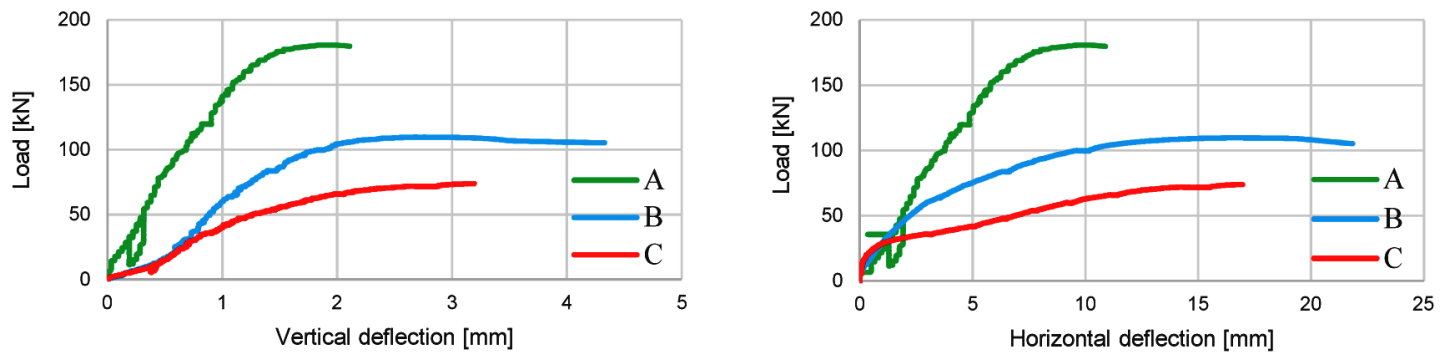

Fig. 3. Load-deflection curve in the vertical and horizontal direction for specimens A, B and C

the beginning, the web horizontal deformation increases. As the yielding in the flange continues the buckling shape of the flange is crucial for the behaviour, and the direction of the horizontal deformation in the web is turned.

The results show that adding a flange with very small stiffness has a large influence on the resistance. With the increasing flange stiffness, the haunch's resistance increases. When the flange stiffness is high enough then the web thickness is not crucial for the resistance and may be reduced. It is observed that with increasing flange stiffness the haunch's resistance is increasing rapidly. In the tested case the haunch's resistance increased ten times. On the other side a haunch with a flange with reduced stiffness has lower resistance, which could be in many connection configurations sufficient and material saving. Recommendations for these configurations with decreased flange stiffness are not covered in the current Eurocode and the design of haunches with low flange stiffness requires special attention, especially when stability problems occur.

\section{Validation of the numerical model}

For further investigations, RFEA is developed and numerical studies are carried out. The numerical analyses are completed by the RFEM 5.0 (Dlubal RFEM) finite element program system. The purpose of validation is to verify the behaviour of the haunch with and without a flange.

The materials are endowed with non-linear properties. The numerical analysis is sensitive to the mesh, so the mesh should be fine enough. To capture the accurate stress distribution in the region around weld cut-outs where yielding is likely to initiate, an intensive mesh is created. The welds between plates are neglected in order to simplify the FE model.

The geometric details of all haunches modelled in FEA are the same as those of the test specimens. The whole specimen is modelled, because the specimens are not symmetric, as is proved by measurement. The numerical models of a haunch without a flange are shown in Figure 8 and with a flange in Figure 9.

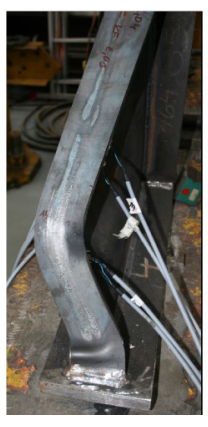

Fig. 4. Specimen D after testing
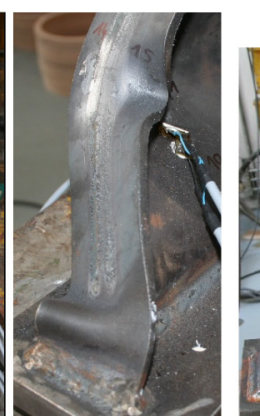

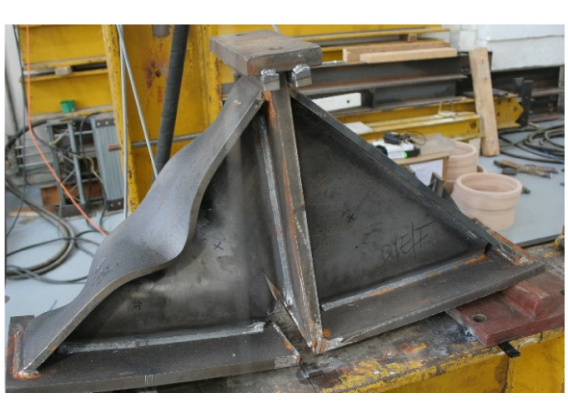

Fig. 5. Specimen E after testing

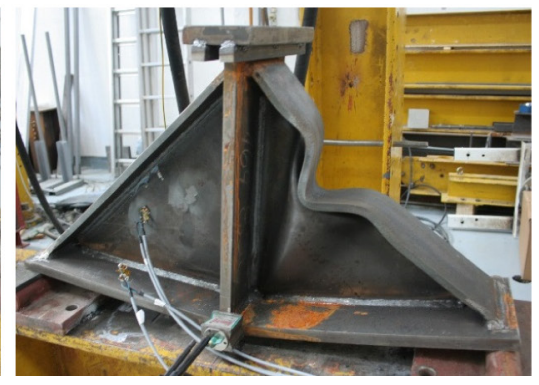

Fig. 6. Specimen F after testing
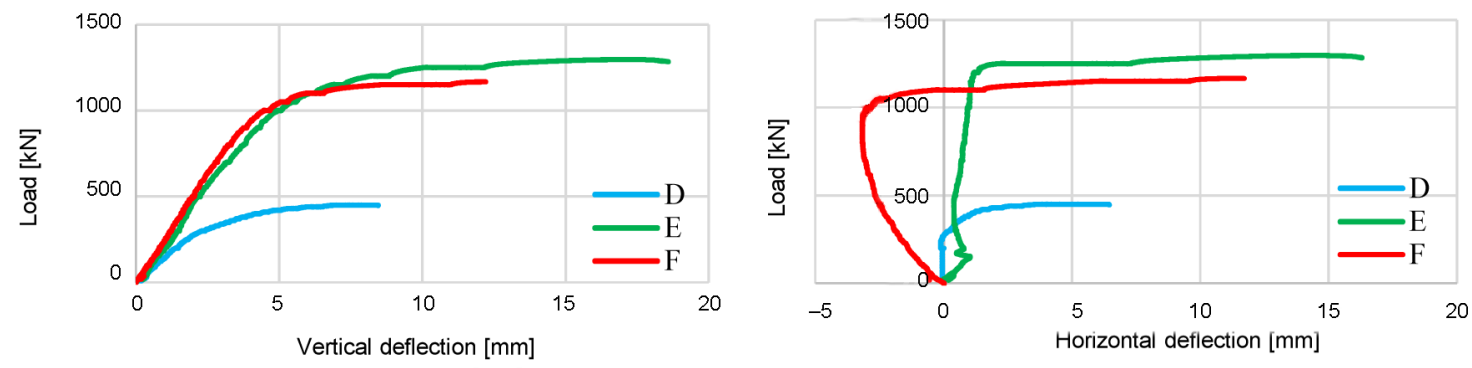

Fig. 7. Load-deflection curve in the vertical and horizontal direction for specimens D, E and F 


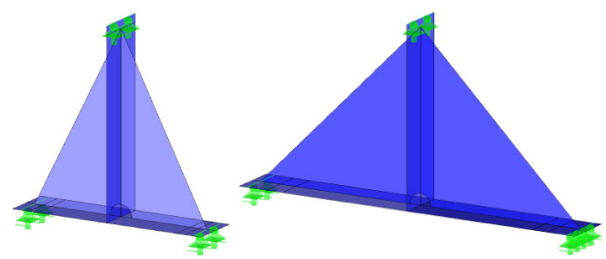

Fig. 8. Research FEA models of a haunch without a flange

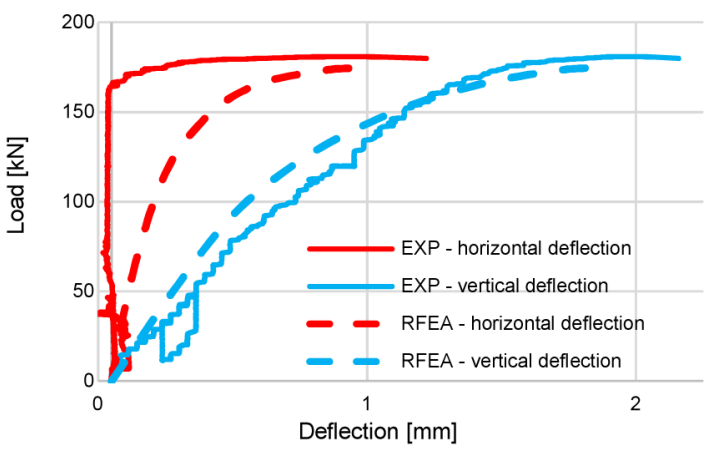

Fig. 10. Load-deflection curve for specimen A

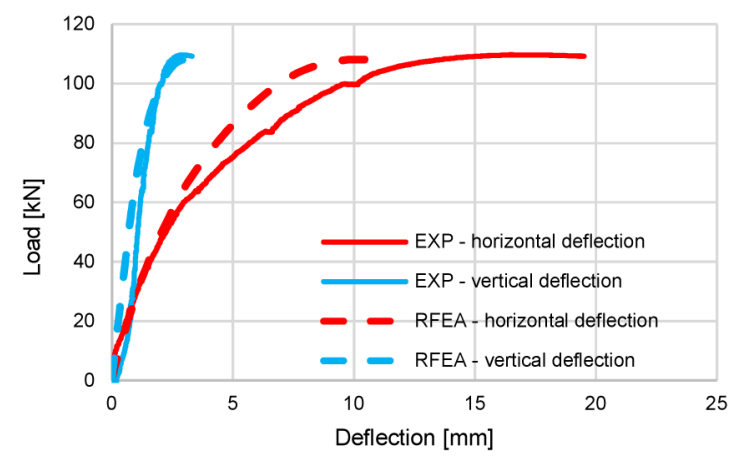

Fig. 11. Load-deflection curve for specimen B

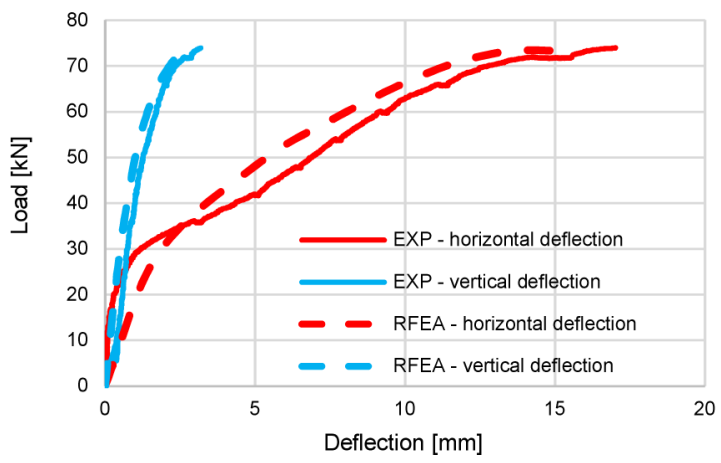

Fig. 12. Load-deflection curve for specimen C

The most common material diagrams, which are used in finite element modelling, are the ideal plastic or elastic model with strain hardening and the true stressstrain diagram. In this study, the material properties of mild steels at ambient temperature are obtained according to tensile tests and the true stress-strain diagram is calculated. The input mechanical properties of steel plates in
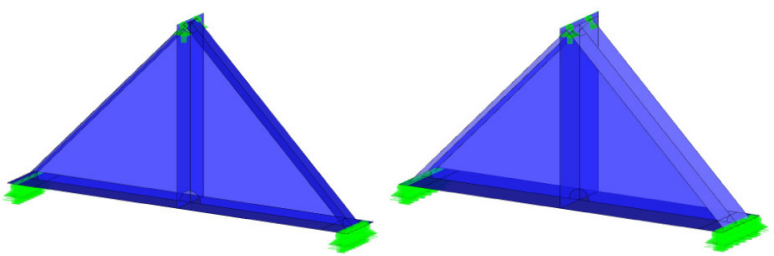

Fig. 9. Research FEA models of a haunch with a flange

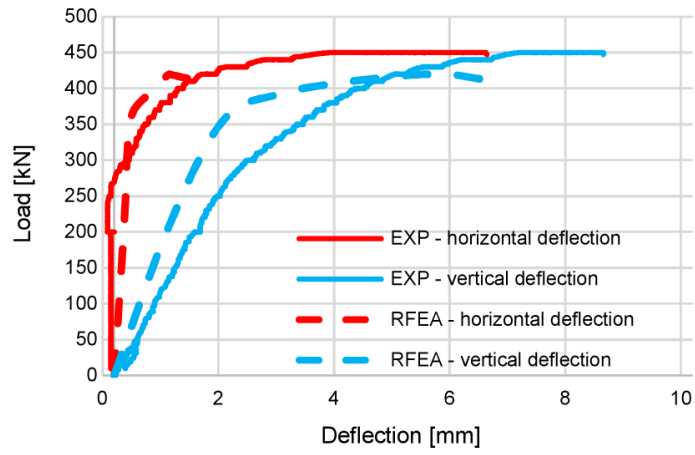

Fig. 13. Load-deflection curve for specimen D

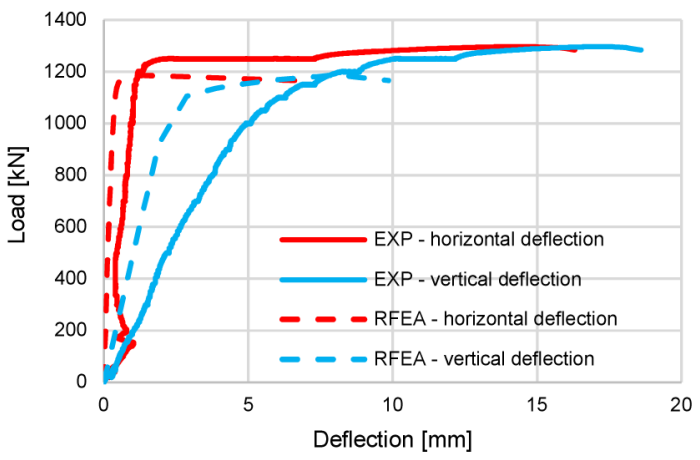

Fig. 14. Load-deflection curve for specimen E

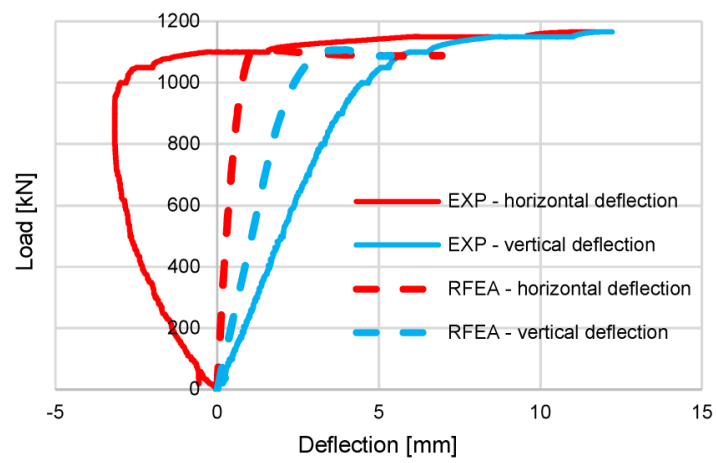

Fig. 15. Load-deflection curve for specimen F

this FEA modelling are true plastic strain, true stress and Young's Modulus. The material characteristics are summarised in Table 1. The material properties for a plate thickness of $20 \mathrm{~mm}$ are not measured, thus the ideal plastic material diagram with strain hardening is used in the analysis. 

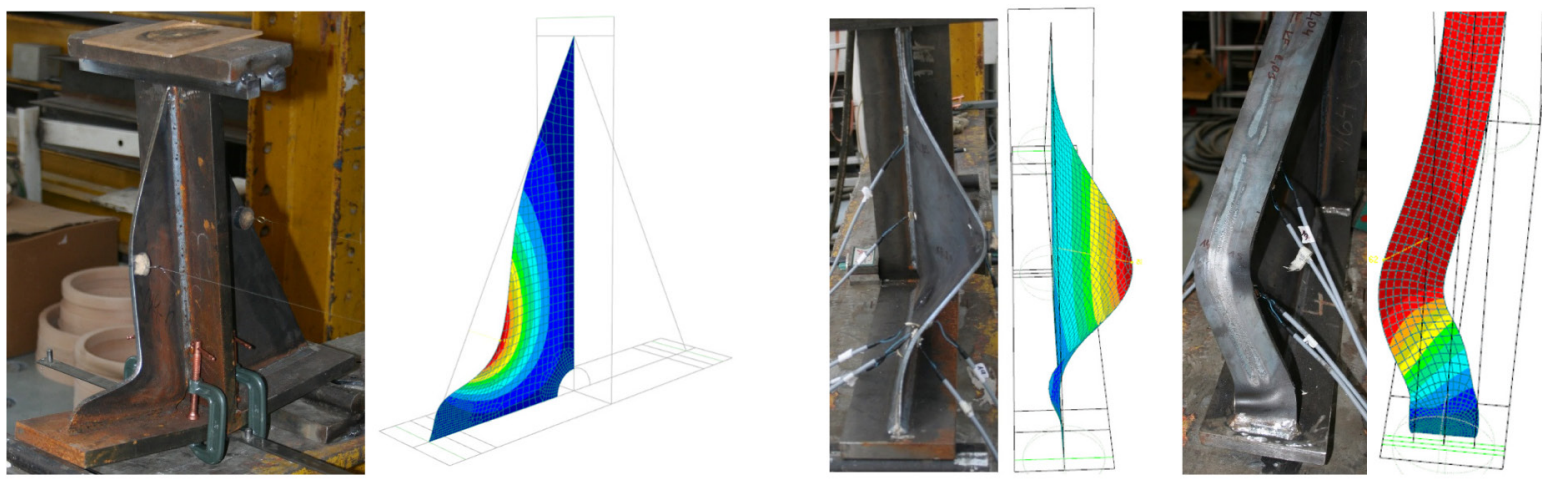

Fig. 16. Experimental and numerical deflection of specimens A, B and D after failure

In the numerical model, 4-node quadrilateral shell elements with nodes at its corners are applied with a maximum side length of $10 \mathrm{~mm}$. Six degrees of freedom are in every node: 3 translations $\left(\mathrm{u}_{\mathrm{x}}, \mathrm{u}_{\mathrm{y}}, \mathrm{u}_{\mathrm{z}}\right)$ and 3 rotations $\left(\varphi_{\mathrm{x}}, \varphi_{\mathrm{y}}, \varphi_{\mathrm{z}}\right)$. To capture the accurate stress distribution in the region around weld cut-outs and supports a concentrated mesh is applied with the finite element length equal to $2 \mathrm{~mm}$.

Material and geometric nonlinear analysis with imperfections (GMNIA) is applied. Equivalent geometric imperfections are derived from the first buckling mode and the amplitude is set according to Annex C EN 19931-5:2008. Residual stresses are neglected. Large deformation analysis is used and the Newton-Raphson method for solving systems of equations is chosen. The number of loading steps is set to 50 , the convergence criteria for tolerance to $1.0 \%$ and the maximum number of iterations to 50. Loading is applied through displacement increments, which better reflect the experiment conditions. The analysis stops at a certain limit of displacement.

The comparisons of RFEA and experimental tests of the load-deflection behaviour of the tested specimens are shown in Figures 10-15. It can be seen that good agreements exist in general. Especially for the specimens without a flange, as shown in Figure 11 and Figure 12, the numerical load-deflection relationship agrees very well with that from the experimental tests on the initial stiffness, resistance and the deflection at the maximum load level. It can be found that the load-deflection curves for the specimens with a flange, as shown in Figures 13-15 differ in the initial stiffness significantly. The difference is caused by the stiffness of supports and stiffness in point, where the load is applied. The supports were modelled as hinge. The comparison of resistances shows good agreement. The peak loads of all specimens obtained from numerical modelling are validated against the experimental results and listed in Table 3. The difference in loads is less than $10 \%$ in all cases.

The comparisons of the final deformation states of all connections between numerical simulations and experimental results are performed at the end of the tests. The comparison of the deformation of specimen A, B and $\mathrm{D}$ after failure with RFEA are presented in Figure 16.
Table 3. Comparison of numerical tests against experimental study

\begin{tabular}{c|c|c|c}
\hline & Load - Test & Load - RFEA & Difference \\
\hline Specimen & {$[\mathrm{kN}]$} & {$[\mathrm{kN}]$} & {$[\%]$} \\
\hline A & 180.7 & 175.2 & 3 \\
B & 109.7 & 108.1 & 1 \\
C & 74.2 & 73.4 & 1 \\
D & 450.0 & 419.5 & 7 \\
E & 1296.0 & 1184.9 & 9 \\
F & 1165.9 & 1106.6 & 5 \\
\hline
\end{tabular}

The experimental final deformation state and the numerical contour plots of the von Mises stress are discussed and the yield line patterns are compared. The comparison of the failure mode similarly concludes that the RFEA of the haunch without a flange is reliable: the virtual experiment leads to the same failure as observed in the tests. As a consequence, the developed model well reflects the actual behaviour of the haunches, thus it is applicable in further studies. By numerical simulation, all the relevant details can be considered, and as the results prove, advanced numerical simulation may be rewarding.

\section{Numerical study}

Simultaneously to physical tests, a numerical study that is defined as a full non-linear simulation - is executed. The numerical study of actual tests on haunches and haunches in beam-to-column joints supported the development and verification of CBFEM. Material and geometrical non-linearity with imperfections is taken into account. An ideal plastic material model with strain hardening, to overcome numerical instability, is chosen and the von Mises yield criterion is applied. Geometrical imperfections are derived from the first buckling mode. Large deflections are considered in the analysis. The iteration is completed on the basis of the Newton-Raphson method. The number of loading steps is set to 50 , the convergence criteria for tolerance to $1.0 \%$ and the maximum number of iterations to 50. Displacement-controlled calculations are completed, i.e. loading is represented by 


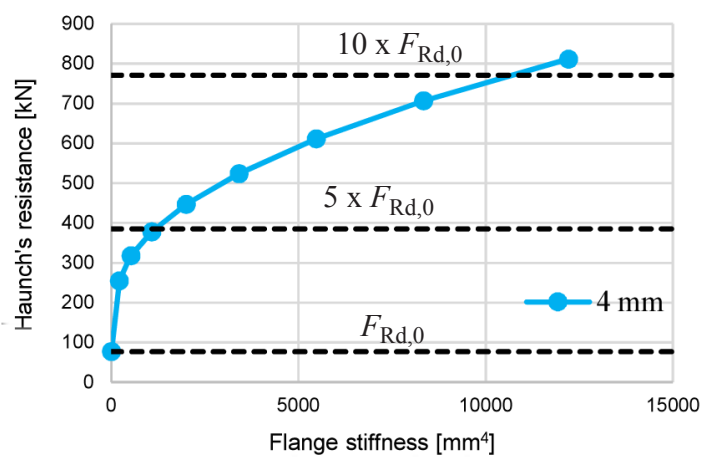

Fig. 17. Relation between resistance of the haunch and flange stiffness

gradually increasing displacements. The analysis proceeds up to a certain set limit of displacement.

\subsection{Numerical study of haunches}

A set of haunches with a varying flange stiffness and web thickness is studied. Web thicknesses are changing from 4 to $6 \mathrm{~mm}$, flange thicknesses are increasing from 4 to $12 \mathrm{~mm}$ and flange widths from 40 to $120 \mathrm{~mm}$. A diagram indicating the relation between the flange stiffness and the haunch resistance is shown in Figure 17. A curve for a web thickness of $4 \mathrm{~mm}$ is displayed as exemplary. It is observed that with the increasing flange stiffness the haunch's resistance is growing. The haunch's resistance is increased more than ten times in the performed numerical study. On the other hand, a haunch with a flange with a reduced stiffness has lower resistance, which could be sufficient in many connection configurations. Recommendations for these configurations with a decreased flange stiffness are not covered in the current Eurocode and the design of haunches with a lowered flange stiffness requires special attention, especially when stability problems occur.

\subsection{Numerical study of a haunch in a beam-to-column joint}

The joint arrangement in the experimentally tested frame is simplified in order to avoid an undesirable effect of other components on the haunch's load carrying capacity. The study was only concentrated on the flange stiffness effect. The numerical study is extended by a model of a haunch in a beam-to-column joint to describe the actual behaviour of haunches in real structural steel joints. The haunch geometry, FEA analysis, meshing and calculation settings are the same. The beam-to-column joint is loaded by the bending moment and additionally supported to avoid out of plane buckling. The influence of the flange stiffness on the joint's design resistance is shown in Fig. 18. The displayed curve belongs to a haunch with a web thickness of $4 \mathrm{~mm}$. The bending resistance of a joint with the highest flange stiffness is increased by $60 \%$ in comparison with a joint with a haunch without a flange.

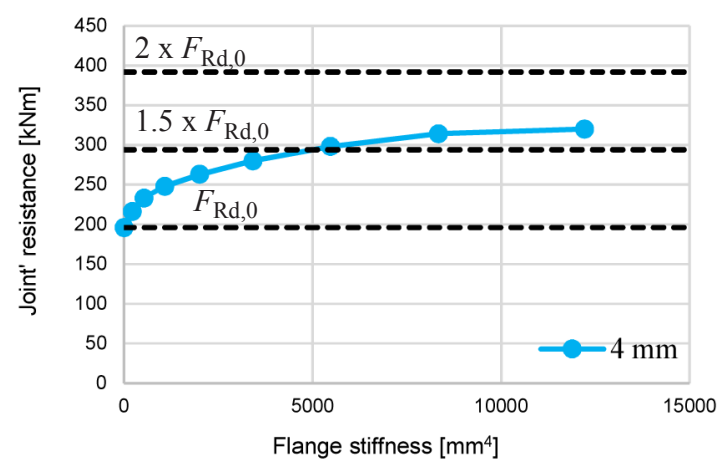

Fig. 18. Relation between joint resistance and flange stiffness

\section{Conclusions}

The article presents experimental and numerical results of six specimens of haunches with and without flanges. The results show that the presence of a flange gives a multiple increase in the haunch's resistance compared to a haunch without a flange. The design of the haunch without a flange in steel joints is complicated especially because of possible plate buckling. The stiffness of the additional flange is a key parameter for the haunch design. The haunch's resistance is increased with increasing flange stiffness. The contribution of web thickness is, for certain flange stiffness, negligible for haunch's resistance as was observed on the comparison of specimen $\mathrm{E}$ and $\mathrm{F}$. The numerical study presents research into advanced numerical modelling of joints with haunches in order to study the influence of the flange stiffness on the joint's load bearing capacity. It is proved that the results of RFEA are in good accordance with the experimental results for all tested specimens, therefore, it can be used to predict the actual behaviour of haunches in structural steel joints. The validation is performed on the load-deflection curve, failure mode, stress distribution and yield line pattern. The maximal difference is $10 \%$, which is considered as a very good agreement. The validation is followed by a numerical study. The results prove that the joint's resistance is influenced by the flange stiffness. The increase of the resistance in a beam-to-column joint strengthened by a haunch is significant compared to a similar joint without a haunch. For stiffeners on the compression side, rules EN 1993-1-8 are set, which limit plates to the third class and better. Recommendations for the fourth class plates are not available. Material and geometric nonlinear analysis with imperfections, which is used in RFEA, is one of possible approaches to the design of slender plates in structural steel joints. Due to the difficulties in entering imperfections to advanced numerical models and the time-consuming calculation, RFEA is not applicable in current practice. It is proposed to use a design procedure combining material nonlinear and buckling analysis without applying imperfections, see (Kurejková et al. 2015) and (Gödrich et al. 2014), in design FEA models (DFEA) and component based FEA models (CBFEM), see (Wald 
et al. 2014). The design procedure will be verified on RFEA.

\section{Acknowledgements}

This study was carried out with support by the Grant Agency of the Czech Technical University in Prague [grant number SGS15/140/OHK1/2T/11].

\section{References}

Abidelah, A.; Bouchair, A.; Kerdal, D. 2012. Experimental and analytical behavior of bolted end-plate connections with or without stiffener, Journal of Constructional Steel Research 76: 13-27. https://doi.org/10.1016/j.jcsr.2012.04.004

Bursi, O.; Jaspart, J. 1997. Benchmarks for finite element modelling of bolted steel connections, Journal of Constructional Steel Research 43(1-3): 17-42. https://doi.org/10.1016/S0143-974X(97)00031-X

Dlubal RFEM 5.0 user's manual [online], [cited 10 Sep 2016]. Available from Internet: https:/www.dlubal.com/en/manuals-for-category-finite-elements.aspx

EN 1993-1-5:2008. Eurocode 3: Design of steel structures Part 1-5: Plated structural elements. CEN.

EN 1993-1-8:2006. Eurocode 3: Design of steel structures Part 1-8: Design of joints. CEN.

Gödrich, L.; Kurejková, M.; Wald, F. 2014. The bolts and compressed plates modelling, in Proceedings of the $12^{\text {th }}$ International Conference on Steel, Space and Composite Structures, 28-30 May 2014, Prague, Czech Republic.

Hoang, V.-L.; Jaspart, J.-P.; Demonceau, J.-F. 2014. Hammer head beam solution for beam-to-column joints in seismic resistant building frames, Journal of Constructional Steel Research 103: 49-60. https://doi.org/10.1016/j.jcsr.2014.08.001

Kurejková, M.; Wald, F. 2014. Compressed stiffeners in structural connections, in Proceedings of Eurosteel 2014, 1012 September 2014, Napoli, Italy.

Kurejková, M.; Wald, F.; Kabeláč, J.; Śabatka, L. 2015. Slender compressed plate in component based finite element mod$\mathrm{el}$, in $2^{\text {nd }}$ International Conference on Innovative Materials, Structures and Technologies, 30 September - 2 October 2015, Riga, Latvia. https://doi.org/10.1088/1757-899x/96/1/012050

Lachal, A.; Aribert, J.; Loho, G. 2005. Static design and cyclic behaviour of end-plate steel and composite joints strengthened by haunches, Advanced Steel Structures 2: 13531358. https://doi.org/10.1016/b978-008044637-0/50201-8

Laustsen, B.; Nielsen, M.; Hansen, T.; Gath, J. 2012. Stability of brackets and stiffeners in steel structures, Steel Construction 5: 138-144. https://doi.org/10.1002/stco.201210017
Lee, C.-H. 2002. Seismic design of rib-reinforced steel moment connections based on equivalent strut model, Journal of Structural Engineering 128: 1121-1129. https://doi. org/10.1061/(ASCE)0733-9445(2002)128:9(1121)

Lee, C.-H.; Jung, J.-H.; Oh, M.-H.; Koo, E.-S. 2003. Cyclic seismic testing of steel moment connections reinforced with welded straight haunch, Engineering Structures 225(14): 1743-1753. https://doi.org/10.1016/S0141-0296(03)00176-7

Martin, L. 1979. Methods for the limit state design of triangular steel gusset plates, Building and Environment 14: 147-155. https://doi.org/10.1016/0360-1323(79)90020-9

Robinson, S. 1983. Failure of steel gusset plates: PhD thesis. The University of Aston in Birmingham: Department of Civil Engineering and Construction.

Salmon, C. G.; Buettner, D. R.; O'Sheridan, T. C. 1964. Laboratory investigation of unstiffened triangular bracket plates, Journal of the Structural Division 90(2): 357-378.

Shakya, S.; Vinnakota, S. 2008. Design aid for triangular bracket plates using AISC specifications, Engineering Journal 45(3): 187-196.

Shanmugam, N. E.; Ng, Y. H.; Richard Liew, J. Y. 2002. Behaviour of composite haunched beam connection, Engineering Structures 24(11): 1451-1463.

Shi, Y.; Shi, G.; Wang, Y. 2007. Experimental and theoretical analysis of the moment-rotation behaviour of stiffened extended end-plate connections, Journal of Constructional Steel Research 63: 1279-1293.

Vigh, L.; Dunai, L. 2010. Advanced stability analysis of regular stiffened plates and complex plated elements, in Proceedings of SDSS'Rio 2010 Stability and Ductility of Steel Structures, 8-10 September 2016, Rio de Janeiro, Brazil.

Wald, F.; Gödrich, L.; Šabatka, L.; Kabeláč, J.; Navrátil, J. 2014. Component based finite element model of structural connections, in Proceedings of the $12^{\text {th }}$ International Conference on Steel, Space and Composite Structures, 28-30 May 2014, Prague, Czech Republic.

Yu, Q.-S.; Uang, C.-M.; Gross, J. 2000. Seismic rehabilitation design of steel moement connection with eelded haunch, Journal of Structural Engineering 126(1): 69-78. https://doi.org/10.1061/(ASCE)0733-9445(2000)126:1(69)

Zhao, W.; Quian, L. 2011. Design approach of stiffeners and model of the initial stiffness in extended end-plate connection, Advanced Materials Research 243-249: 942-947.

Zoetemeijer, P. 1981a. Bolted connections with flush endplates and haunched beams. Report 6-81-15. Delft University of Technology.

Zoetemeijer, P. 1981b. Bolted beam to column knee connections with haunched beams. Report 6-81-23. Delft University of Technology.

Marta KUREJKOVÁ. PhD student of Steel Structures at the Department of Steel and Timber Structures at the Faculty of Civil Engineering of the Czech Technical University in Prague. She received the Master degree in the Structural and Transportation Engineering from the Czech Technical University in Prague and started PhD studies in 2013. She has published several articles and papers in the buckling in steel structures joints and stiffeners design.

František WALD. Professor and Head of the Department of Steel and Timber Structures at the Faculty of Civil Engineering of Czech Technical University in Prague. He finished the Ph.D. degree in Steel structures at the CTU Prague in 1982. He is since 1995 associate professor, since 2001 professor and since 2004 head of the Department of Steel and Timber Structures. His current research interests include connection design, structural fire design, aluminium structures, scaffoldings and sandwich panels. 